Redaktionelle Verantwortung: FMH SERVICES

\title{
Umfassende Versicherung für Ihre Praxis
}

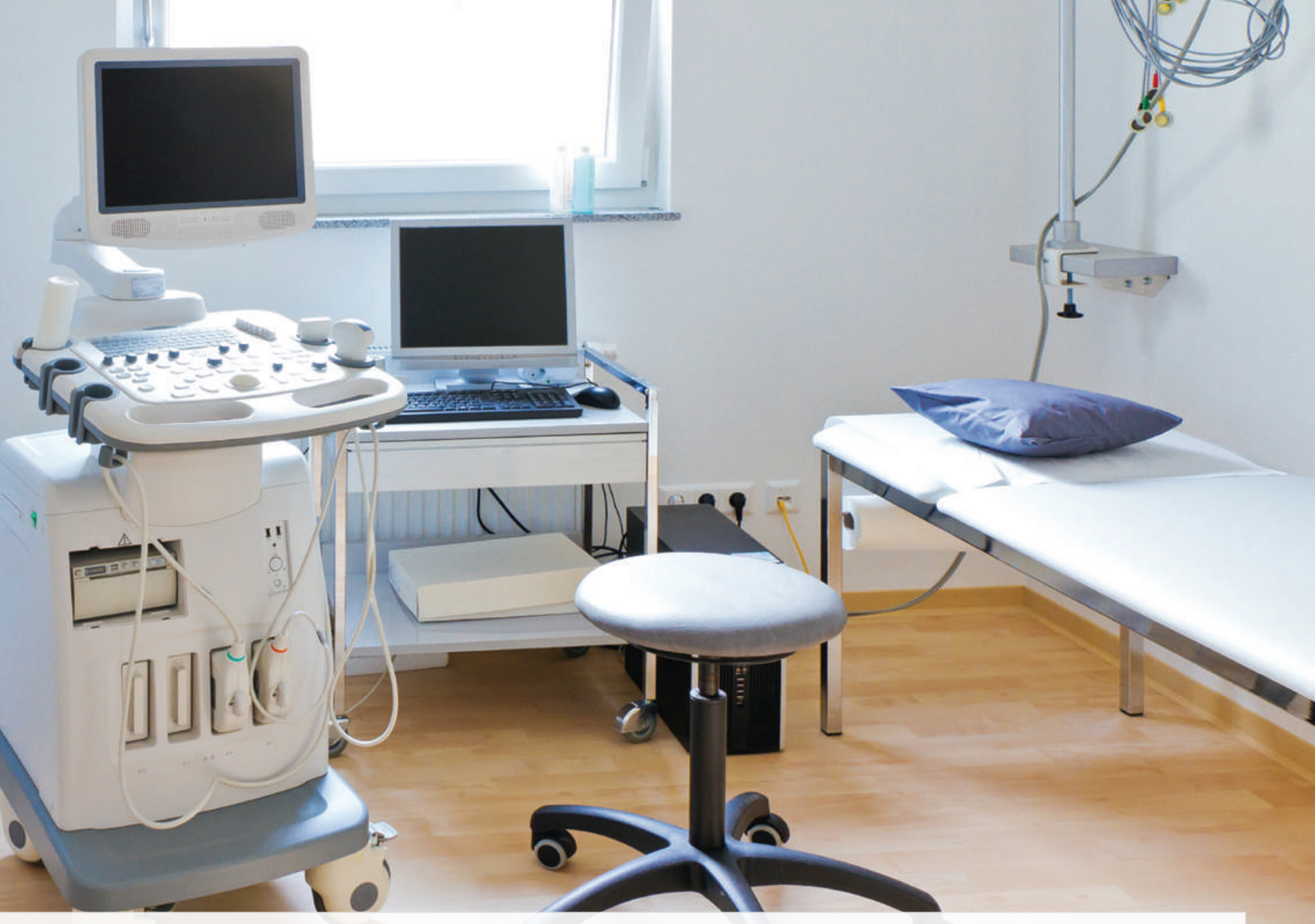

Kennen Sie die FMH Insurance Services Praxisversicherung, welche speziell für die Bedürfnisse der Ärzteschaft entwickelt wurde? FMH Services Mitglieder profitieren dabei von attraktiven Spezialkonditionen. Gerne erstellen wir Ihnen eine kostenlose und unverbindliche Vergleichsofferte zu Ihrer bestehenden Lösung und zeigen Ihnen Ihr Einsparpotential auf. Prüfen Sie unser Angebot, um umfassend versichert zu sein und Prämien zu sparen!

\section{PRAXISVERSICHERUNG}

$\square \quad$ Ich möchte eine kostenlose und unverbindliche Offerte der FMH Insurance Services Praxisversicherung. (Bitte Kopie der aktuellen Versicherungspolice beilegen.)

$\square \quad$ Ich wünsche eine persönliche Beratung. Bitte rufen Sie mich an.

Vorname / Name

Adresse

PLZ / Ort

Telefon Privat / Geschäft

Beste Zeit für einen Anruf

E-Mail-Adresse

Bitte Antworttalon einsenden oder per Fax an 0319595010

\section{FMH INSURANCE}

Roth Gygax \& Partner AG - Koordinationsstelle Moosstrasse 2, 3073 Gümligen Tel. 0319595000 - Fax 0319595010 mail@fmhinsurance.ch - www.fmhinsurance.ch 